\title{
LIGHT CONTROL OF PLANT DEVELOPMENT
}

\section{Christian Fankhauser and Joanne Chory}

Plant Biology Laboratory, The Salk Institute for Biological Studies, La Jolla,

California 92037; e-mail: chory@ salk.edu

KEY WORDS: Arabidopsis, light, signal transduction, photoreceptors

\begin{abstract}
To grow and develop optimally, all organisms need to perceive and process information from both their biotic and abiotic surroundings. A particularly important environmental cue is light, to which organisms respond in many different ways. Because they are photosynthetic and non-motile, plants need to be especially plastic in response to their light environment. The diverse responses of plants to light require sophisticated sensing of its intensity, direction, duration, and wavelength. The action spectra of light responses provided assays to identify three photoreceptor systems absorbing in the red/far-red, blue/near-ultraviolet, and ultraviolet spectral ranges. Following absorption of light, photoreceptors interact with other signal transduction elements, which eventually leads to many molecular and morphological responses. While a complete signal transduction cascade is not known yet, molecular genetic studies using the model plant Arabidopsis have led to substantial progress in dissecting the signal transduction network. Important gains have been made in determining the function of the photoreceptors, the terminal response pathways, and the intervening signal transduction components.
\end{abstract}

\section{CONTENTS}

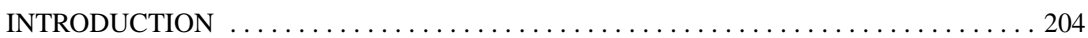

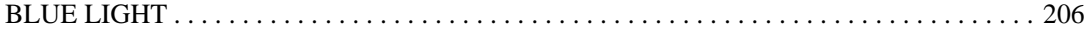

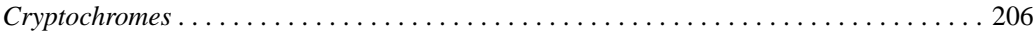

Blue Light-Mediated Phototropism .................................... 207

$U V-B, U V-A$ and Additional Blue Light Receptors . . . . . . . . . . . . . . . 208

PHYTOCHROMES ............................................. 209

Structure and Function Analysis . . . . . . . . . . . . . . . . . . . . . . . . . . . . . . 209

Specific Functions for Individual Phytochromes . . . . . . . . . . . . . . . . . . . 213 
PHYTOCHROME AND CRYPTOCHROME SIGNAL TRANSDUCTION . . . . . . . . . . . 217

Positively Acting Factors . . . . . . . . . . . . . . . . . . . . . . . . . . . . . . . . . . . 217

Repressors of Photomorphogenesis ............................. 220

Light Signaling and Circadian Rhythms ......................... 223

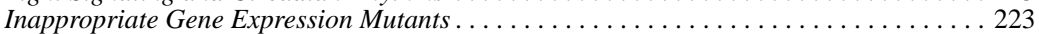

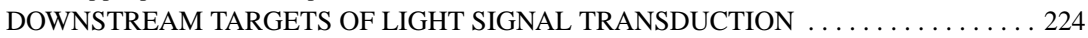

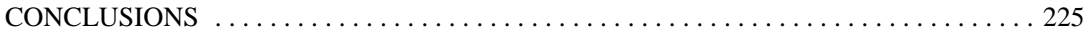

\section{INTRODUCTION}

Light affects every aspect of plant development, beginning with seed germination. After germination, the very young seedling must choose between two developmental pathways depending on the available light. In the absence of light, the seedling grows heterotrophically, using the seed's resources in an effort to reach light. This etiolated stage is characterized by a long hypocotyl (primary stem), an apical hook, and unopened cotyledons (embryonic leaves), features that allow the seedling to grow through a layer of soil and emerge in the light (Figure 1a). Once the seedling perceives sufficient light, it will deetiolate, a developmental process that optimizes the body plan of the seedling for efficient photosynthetic growth (Figure $1 b$ ). During de-etiolation, the rate of hypocotyl growth decreases, the apical hook opens, cotyledons expand, chloroplasts develop, and a new gene expression program is induced. Moreover, during vegetative growth, light availability is a crucial factor regulating appropriate responses to competition from neighbors. Light also strongly influences the transition from vegetative to reproductive development, which in turn allows the seed to start the next cycle.

Plants respond to a broad spectrum of light, ranging from UV-B to far-red light. A large body of physiological, photobiological, and molecular genetic studies have demonstrated that plants possess distinct photoreceptors sensing UV-B, UV-A, blue, green, red, and far-red light (Kendrick \& Kronenberg 1994). Plants also sense the duration, intensity, and direction of light using these same photoreceptors. Plant responses to light of varying intensity have been subdivided into three categories: the very low fluence (VLF) responses, which are initiated by as little as $100 \mathrm{pmol} \cdot \mathrm{m}^{-2}$ fluences (e.g. transcription of certain photosynthetic genes); the low fluence (LF) responses, which require $1 \mathrm{mmol} \cdot \mathrm{m}^{-2}$ fluences (e.g. germination of lettuce seeds); and high irradiance (HI) reactions, which require prolonged exposure to high fluence rate light in excess of $10 \mathrm{mmol}$ $\cdot \mathrm{m}^{-2}$ (e.g. inhibition of hypocotyl elongation). Of the various photoreceptors, the most intensively studied is a family of photoreversible red/far-red absorbing chromoproteins called phytochromes (Butler et al 1959, review in Quail et al 1995). Cryptochrome, a UV-A/blue light receptor, was described recently (Ahmad \& Cashmore 1993). This name hints at its elusive nature (blue light 


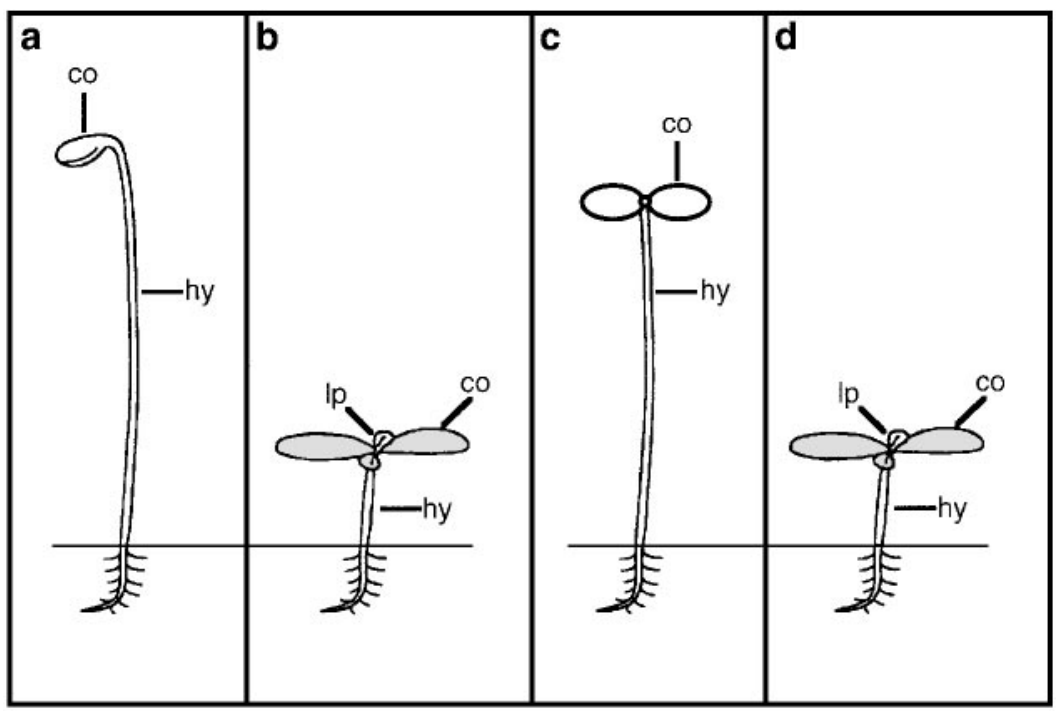

Figure 1 Schematic representation of wild-type and mutant Arabidopsis seedlings grown in the light or in the dark. (a) Dark-grown wild-type seedling; $(b)$ wild-type seedling grown in the light; $(c)$ photoreceptor mutant grown in the light; $(d)$ mutant that de-etiolates in the dark. Hypocotyl hy, cotyledon co, leaf primodia $1 \mathrm{p}$.

responses in plants were described more than a century ago by Darwin) and to the prevalence of blue light responses in cryptogams (non-flowering plants). The search for other photoreceptors is ongoing.

The light-dependent development of plants, a process called photomorphogenesis, has been studied for over a hundred years in a wide variety of plant species. In recent years, research has concentrated on a few species that are particularly well-suited for molecular genetic studies. Due to its small stature and genome size, its short life cycle, and the ease with which it can be propagated, Arabidopsis thaliana has become a key plant in the study of photomorphogenesis. Genetic screens yielded several photoreceptor mutants, and to date in Arabidopsis, five phytochromes and two cryptochromes have been identified, but several well-characterized light responses are sensed by unknown receptors. In addition to a wealth of mutants, an Arabidopsis genome project is now well under way. The hope is that within a few years mutant studies and the subsequent molecular identification of the impaired gene will become routine. We therefore deal solely with recent studies performed in Arabidopsis.

Genetic dissection of light responses in Arabidopsis has implicated more than 50 loci in the light-signaling network controlling plant development. Although a number of important players-including the photoreceptors and downstream 
elements in light-regulated promoters-have been identified, the mechanism by which the photoreceptors transmit a signal and the nature of the signal amplification cascade is still very sketchy. In this review, we discuss primarily the most recent advances in photoreceptor function and structure and, secondarily, the genetics and biochemistry of light signaling. For other points of view and more detail on light signal transduction, see the following: Terzaghi \& Cashmore 1995, Chory et al 1996, Wei \& Deng 1996, Barnes et al 1997.

\section{BLUE LIGHT}

A large number of blue light responses have been documented in plants, including inhibition of the rate of hypocotyl growth, phototropism, stomatal opening, and the induction of gene expression. In the following paragraphs, we concentrate on the identification of cryptochrome 1 and its role in the hypocotyl growth inhibition response and the biochemistry and genetics of phototropism.

\section{Cryptochromes}

The identification of an Arabidopsis mutant, hy4, impaired specifically in blue light perception (Koornneef et al 1980) allowed the cloning of the first blue light receptor, CRY1, from plants (Ahmad \& Cashmore 1993, 1996a). CRY1 is a soluble, ubiquitously expressed protein whose expression does not appear to be regulated by light. CRY1 consists of two domains: an N-terminal portion with significant identity to bacterial photolyases and a 200 -amino acid C-terminal extension sharing some similarity with tropomyosin. Biochemical characterization has shown that despite its homology to bacterial photolyases, CRY1 has no photolyase activity (Malhotra et al 1995, Lin et al 1995b). The similarity between CRY1 and DNA photolyases is highest in the chromophore-binding domains of photolyases. In vitro experiments with recombinant CRY1 have shown that a FAD (flavin adenine dinucleotide) and a pterin (methenyltetrahydrofolate) bind to CRY1 (Malhotra et al 1995, Lin et al 1995b). In photolyases, UV-A light is first absorbed by a pterin-like molecule, which is bound to the $\mathrm{N}$ terminus of the protein (reviewed in Sancar 1994). The absorption spectrum of the pterin determines the action spectrum of photoreactivation. Photon energy is then transferred to the C-terminal-bound FAD chromophore, which donates the electron that participates in the cleavage of the pyrimidine dimer of UV-damaged DNA. The cofactor composition of CRY1 is in agreement with the lack of response that hy4 mutants show primarily in blue and, to a lesser extent, in UV-A and green light. To absorb green light, however, the FAD chromophore must be in the neutral radical flavosemiquinone (FADH) state, which is normally unstable but has been observed in recombinant CRY1 purified from baculovirus (Lin et al 1995b). As such, it appears that CRY1 has retained the 
light receptor part of the bacterial photolyases but transduces the light signal by some different mechanism.

Sequencing of numerous hy4 mutant alleles has demonstrated that both domains are essential for CRY1 function (Ahmad et al 1995). Four independent point mutations have been found in the predicted flavin-binding domain of CRY1, a domain required for activity of the Escherichia coli photolyases. One particularly informative allele presumably disrupts the binding of the pterin and results in an Arabidopsis mutant unresponsive to UV-A or blue light but responsive to green light. The action spectrum of this mutant suggests an altered CRY1 that binds only a flavin. Seven missense mutations in the C-terminal extension and two nonsense mutations that encode truncated proteins lacking the region of homology to tropomyosin demonstrate the importance of this domain to CRY1 function.

Mutant analysis suggests that CRY1 levels are limiting (hy4 mutants have a semidominant hypocotyl elongation phenotype). Overexpression studies in tobacco and Arabidopsis confirmed this view, as plants containing elevated levels of CRY1 are hypersensitive to UV-A, blue, and green light (Lin et al 1995a, 1996). Genetic analysis indicates that CRY1 is not the only blue light receptor. Phytochrome is also a blue light receptor (discussed below), and other distinct blue light receptors are also present. hy 4 mutants are primarily deficient in the inhibition of hypocotyl elongation and biosynthesis of anthocyanins in response to blue light. Hook and cotyledon opening are affected to a lesser degree. This prompted the search for homologues of CRY1 and, to date, one sequence has been identified in Arabidopsis. This protein, CRY2, possesses an $\mathrm{N}$-terminal photolyase domain similar to that of CRY1 but an entirely divergent C terminus (Ahmad \& Cashmore 1996a; C Lin \& A Cashmore, personal communication). CRY2 shows highest homology to a Sinapis albicans protein that also lacks in vitro photolyase activity (Malhotra et al 1995, Ahmad \& Cashmore 1996a). Plants overexpressing CRY2 have larger cotyledons than wild type when grown in blue light, suggesting that CRY2 plays an important role in cotyledon expansion in response to blue light (C Lin \& A Cashmore, personal communication).

\section{Blue Light-Mediated Phototropism}

Directional growth induced by unequal irradiation of light is known as phototropism (Firn 1994). In young Arabidopsis seedlings this is mainly a blue light response, which is genetically distinct from CRY1. Photobiological experiments suggest that this response is mediated by two pigments: one absorbing in blue light and the other in green (Konjevic et al 1989; reviewed in Short \& Briggs 1994). Mutants affected in shoot phototropism have been isolated in Arabidopsis (Khurana et al 1989, Liscum \& Briggs 1995). Two loci specifically 
affecting root phototropism have also been reported but are not discussed here (Okada \& Shimura 1992).

A number of experiments suggest that the mutant $J K 224$ (now known as NPH1) (Khurana et al 1989), of which additional alleles were isolated by Liscum \& Briggs (1995), is the photoreceptor or at least an early element in the phototropic signaling cascade. In pea seedlings it has been shown that the light fluence requirements for phototropism parallel the phosphorylation of a plasma membrane-associated $120-\mathrm{kDa}$ protein. This phosphorylation goes to completion within minutes (long before any phototropism is seen) and can be recapitulated in vitro by irradiating microsomal preparations of dark-grown seedlings with blue light (reviewed in Short \& Briggs 1995). Blue light-dependent phosphorylation of similarly sized proteins can be detected in a variety of plant species (Reymond et al 1992a). The phototropic mutant JK224 (now known as $n p h 1-2)$ is impaired in its ability to phosphorylate this $120-\mathrm{kDa}$ membrane protein (Reymond et al 1992b). Interestingly, nphl-2 is defective in its response to blue light only, whereas the three other alleles are defective in both blue and green light (Liscum \& Briggs 1995). This situation is reminiscent of what has been observed with mutant alleles of hy4 and suggests that NPH1, like CRY1, might be a photoreceptor with two chromophores. Alternatively, NPH1 might act downstream of two distinct photoreceptors, and the nphl-2 allele could be impaired specifically in an interaction with only one blue light receptor.

Mutants in three other loci (nph2, nph3, previously known as $J K 218$, and nph4) affected in phototropism are still able to phosphorylate the $120-\mathrm{kDa}$ membrane protein, suggesting that these genes act downstream from the receptor (Reymond et al 1992b, Liscum \& Briggs 1995). Additional studies are consistent with NPH2 and NPH3 acting specifically in phototropism signaling, whereas NPH4 is also involved in gravitropism (Liscum \& Briggs 1996).

\section{$U V-B, U V-A$ and Additional Blue Light Receptors}

Numerous blue light reponses have been characterized in great detail at the physiological or gene expression level, but to date no molecular or genetic data link them to a known photoreceptor. A classical example is blue lightmediated stomatal opening, for which the only certainty is that CRY1 is not the photoreceptor.

The expression of a number of genes is regulated by blue light. Only one gene, chalcone synthase $(\mathrm{CHS})$, is known to be regulated by CRY1. $\mathrm{CHS}$ gene expression is a widely used model for blue-, UV-A-, and UV-B-regulated responses. The contribution of light of different wavelengths is clearly separable, and the expression of $C H S$ is synergistically induced if both UV-A and UV-B, or blue and UV-B, but not blue and UV-A, are applied. The role of CRY1 is restricted 
to the blue/UV-A induction (Fuglevand et al 1996). In pharmacological studies using an Arabidopsis cell culture system, it was concluded that both UV-A/blue and UV-B responses require $\mathrm{Ca}^{2+}$, protein kinases and phosphatases, and protein synthesis. Only the UV-B response is affected by a calmodulin antagonist (Christie \& Jenkins 1996). Thus it appears that the UV-B and blue/UV-A responses can be distinguished both genetically and biochemically. Other blue light receptors regulate the expression of different light-regulated genes. For instance, very low fluences of blue light induce the expression of a nuclear photosynthesis gene, $L H C B$, in a phytochrome-dependent manner that is independent of CRY1. The expression of a number of chloroplast-encoded genes requires HI blue light, suggesting that these genes are regulated by an additional receptor (Christopher \& Mullet 1994). As such, it can be inferred that a number (at least three) of blue/UV-A light receptors control light-regulated gene expression in Arabidopsis.

\section{PHYTOCHROMES}

\section{Structure and Function Analysis}

Phytochrome was originally discovered as the phototransducer of red/far-red reversible reactions of plants (Butler et al 1959). In higher plants, phytochromes are encoded by a small gene family (PHYA-PHYE in Arabidopsis) that share between 50 and 80\% identity (Quail et al 1995). Phytochromes are also present in mosses, ferns, and green algae (Pratt 1995). Photobiological and physiological studies demonstrate that phytochromes control processes throughout the plant life cycle (Kendrick \& Kronenberg 1994). Phytochromes are essential for all major developmental transitions such as germination, de-etiolation, and the commitment to flowering. They also fine-tune vegetative development by influencing gravitropism, phototropism, and by mediating the shade-avoidance response (Smith 1995, Parks et al 1996, Robson \& Smith 1996).

Two types of phytochromes have been defined on the basis of their lability in light. Type I phytochromes (phyA in Arabidopsis) are abundant in etiolated seedlings, but their level drops 50 to 100 times in green plants (Quail et al 1995). These phytochromes were the first purified and are the best characterized biochemically. Type II phytochromes are relatively light stable and are the most abundant phytochromes in light-grown plants. phyB and phyC are type II phytochromes; there are no available data on phyD and phyE, which are much less abundant (Somers et al 1991, Quail et al 1995).

The structure and function of phyA has been studied most extensively because it can be purified from etiolated seedlings, where it is present at high levels. PhyAs are homodimers of two $120-\mathrm{kDa}$ soluble proteins, each covalently attached to a linear tetrapyrrole (phytochromobilin) via a thioether linkage to a 
unique cysteine. Phytochrome is synthesized in its red-absorbing form (Pr), which has a major absorption peak at $660 \mathrm{~nm}$, but also absorbs over the whole visible spectrum with a secondary absorption peak around $380 \mathrm{~nm}$ (Figure $2 b$ ). Illumination with red light converts Pr to a far-red absorbing form (Pfr) in a process that involves a $\mathrm{Z}$ to $\mathrm{E}$ isomerization of the $\mathrm{C} 15$ double bond between the C- and D-tetrapyrrole rings (Andel et al 1996). The absorption spectrum

a.

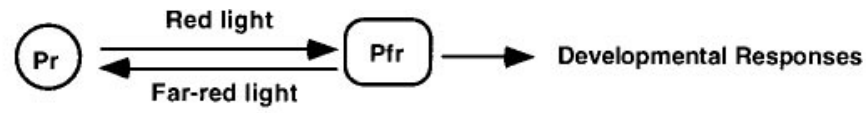

b.

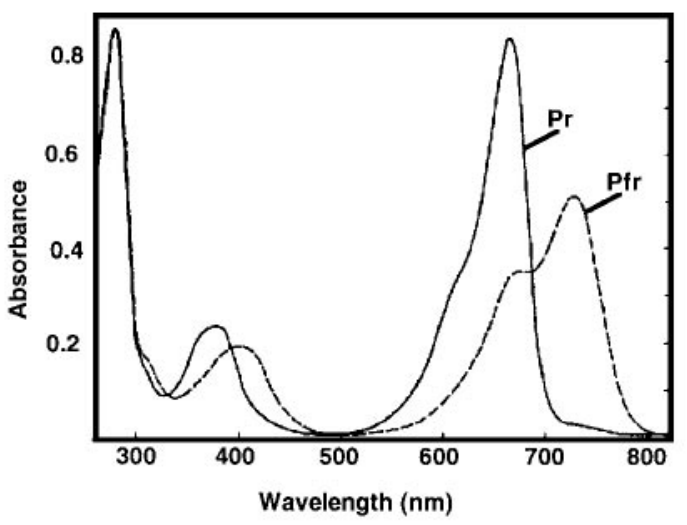

C.

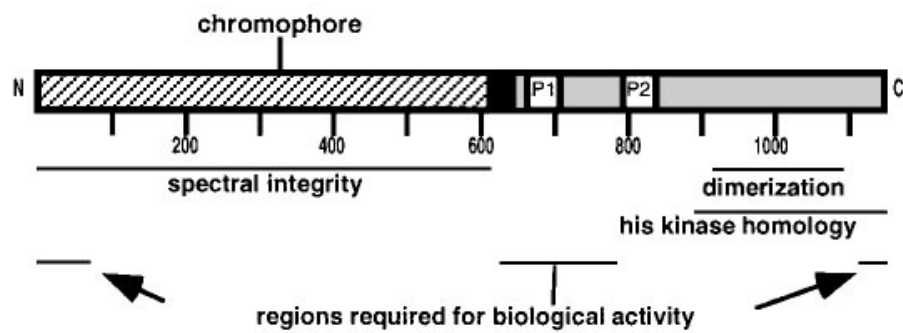

Figure 2 Structural and spectral properties of the phytochrome chromoprotein. (a) Phytochrome exists in two spectrally distinct and interconvertible forms, red and far-red absorbing, Pr and Pfr, respectively. Pfr has been correlated with induction of most developmental responses; $(b)$ absorption spectra of oat phytochrome A as Pr and Pfr (adapted from Kendrick \& Kronenberg 1994); (c) linear representation of the phytochrome protein; P1 and P2 represent the PAS repeats. 
of Pfr overlaps somewhat with Pr, with a major absorption peak at $730 \mathrm{~nm}$ (Figure $2 b$ ). Irradiation of Pfr with far-red light converts it back to Pr. The spectral properties of these two isoforms account for the classical LF red/far-red reversible responses known in plants. Because red light irradiation is correlated with induction of growth and development, Pfr is considered the active form of phytochrome (Figure 2a). However, VLF and HI responses are more difficult to account for in terms of the photochromicity of purified phytochromes. VLF responses, for instance, are not reversible by a subsequent pulse of far-red light. HI responses are even more mysterious because it is still unclear why HI responses are most prevalent in far-red light, conditions in which most phytochromes are presumably in their inactive Pr form (Kendrick \& Kronenberg 1994).

The cloning of the entire gene family from Arabidopsis has allowed the assessment of the spectral properties of different phytochromes. When overexpressed in Arabidopsis, phyB displays spectral properties identical to those of phyA (Wagner et al 1991). Recombinant phyA and phyB purified from a variety of sources (different yeast species and $E$. coli) confirm this view (Kunkel et al 1996). Even recombinant algal phytochrome displays a similar absorption spectrum (Wu \& Lagarias 1996). Thus it is likely that all phytochromes possess similar spectral properties.

The phytochrome chromoprotein is divided into two globular domains: an $\mathrm{N}$-terminal chromophore-binding domain and a C-terminal domain believed to transduce the signal generated by light (Figure 2c) (Jones \& Edgerton 1994, Quail et al 1995). The N-terminal $70 \mathrm{kDa}$ contains the information necessary and sufficient to attach the chromophore and recapitulate the spectral properties of full-length phytochrome. The nature of the signal, presumably generated by the C-terminal third of the protein, is unknown. It has been noted that the $\mathrm{C}$ terminus of phytochrome shares some identity with bacterial histidine kinases (Schneider-Poetsch 1992). Although the last 300 amino acids of phytochrome have been implicated in biological function, no one has definitely proven (or disproven) that phytochrome possesses protein kinase activity. The chromophorebinding domain is separated from the histidine kinase homology domain by a 150 amino acid (aa) spacer with interesting structural properties and clear functional relevance. This domain appears to be a hot spot for missense mutations affecting both phyA and phyB function (Wagner \& Quail 1995, Xu et al 1995, Bradley et al 1996). It contains two direct repeats, each of about 40 aa separated by a linker. The repeats show homology to PAS domains that have been implicated in protein-protein interactions between basic helix-loop-helix/PAS transcription factors such as periodic, arnt, and sim; hence PAS (Lagarias et al 1995). Of note, in Neurospora crassa, the gene products of $W c 1$ and $W c 2$ probably interact via PAS domains and binds to promoters in response to blue light (Linden \& Macino 1997). 
The sequencing project of the cyanobacteria Synechocystis PCC6803 genome has revealed an open reading frame (ORF) with significant identity to higher plant phytochromes (Hughes et al 1997). The cyanobacterial phytochrome homologue is most similar to higher plant phytochromes in the chromophorebinding domain. Recombinant cyanobacterial protein can attach chromophore and has spectral properties similar to higher plant phytochromes (Hughes et al 1997; K-C Yeh \& JC Lagarias, personal communication). The C terminus of PCC6803 phytochrome has clear homology to bacterial histidine kinases (and to a lesser extent to phytochromes). The presence of an ORF with high homology to bacterial phosphorelay proteins in the same operon makes the histidine kinase homology even more likely to be functionally significant. The biological activity of the PCC6803 phytochrome is unknown, but it is likely that work on this prokaryotic protein will provide insight to the mechanism of plant phytochrome signaling.

The sensor for chromatic adaptation (a mechanism by which cyanobacteria optimize photosynthesis in given light conditions) of the filamentous cyanobacteria Fremyella diphosiphon has recently been cloned (Kehoe \& Grossman 1996). This sensor is another example of a potential histidine kinase with an N-terminal extension sharing some homology with the phytochrome chromophore-binding domain. This light sensor RcaE does not possess the invariant Cys that binds the chromophore of plant phytochromes. RcaE transduces the light signal via $\mathrm{RcaC}$, a protein that has significant identity to bacterial phosphorelay proteins, again implicating a histidine kinase phosphorelay mechanism at the heart of this light response system.

The $\mathrm{N}$ and $\mathrm{C}$ termini of phytochrome each possess important biological activity (Cherry et al 1992, 1993). These domains are not highly conserved among various phytochromes, and thus they may represent a structural basis for the different action of these phytochromes. Overexpression of full-length and truncated forms of oat phyA in tobacco has demonstrated that removal of as little as 35 aa at the phytochrome $\mathrm{C}$ terminus destroys its biological activity without affecting its spectral properties or dimerization (Cherry et al 1993). The last 200 aa are required for dimerization of phyA expressed in tobacco, a result that was confirmed using the yeast two-hybrid assay (Cherry et al 1993; C Fankhauser \& J Chory, unpublished data). Circular dichroism and differential phosphorylation indicate that conformational changes occur at the very $\mathrm{N}$ terminus when phytochrome interconverts from Pr to Pfr. In vivo, the reduced biological activity of an oat phyA protein with a deletion of amino acids 7 to 69 further indicates the importance of this domain (Cherry et al 1992). This truncated form of phytochrome also has slightly blue-shifted absorption peaks and slower dark reversion rates. Mutation of the first 10 Ser of phyA to Ala (all contained within the first 20 aa) or deletion of this region 
results in a mutant that is hypersensitive to light (Stockhaus et al 1992, Jordan et al 1996). Previous results had shown that Pr phytochrome is phosphorylated at the $\mathrm{N}$ terminus (Wong et al 1986). Taken together, these results suggest a desensitization mechanism via these serines.

Overexpression of very high levels of phyA or phyB is insufficient to drive de-etiolation in the dark, although these plants show higher sensitivity to light as measured by inhibition of hypocotyl elongation. Overexpression of full-length phytochrome with a mutation in the Cys, which binds to the chromophore (the apoprotein in the absence of chromophore adopts a conformation similar to Pr), does not lead to any phenotypic alteration, suggesting that Pfr mediates the physiological responses (Wagner et al 1996b). Further refined experiments have tried to address the function of various parts of phytochrome, either by deleting regions, as mentioned above, by random mutagenesis of the full-length clone, or, more recently, by domain swapping experiments between phyA and phyB (Boylan et al 1994, Wagner et al 1996a,b). The key importance of the PAS domain of both phyA and phyB was confirmed in these studies. The light lability of phyA appears to reside in its $\mathrm{N}$ terminus. The domain swapping and deletion analysis experiments suggest that the $\mathrm{N}$ terminus of phytochrome is essential for its specific photosensory properties and that the $\mathrm{C}$ termini of phyA and phyB are interchangeable (Wagner et al 1996a). It is important to note, however, that the vast majority of these experiments were done by overexpressing a heterologous phytochrome in a wild-type background. The most extreme example is the swapping experiment where fusion proteins between oat phyA and rice phyB were ectopically expressed in wild-type Arabidopsis. It has been documented that the dark reversion rates and the light lability of monocot and dicot phyAs are quite different. Therefore, these results should be interpreted with caution.

\section{Specific Functions for Individual Phytochromes}

The identification of phytochrome mutants from Arabidopsis and other plants has clarified greatly the overlapping and unique biological function of individual phytochromes. Screens for mutants that show dark-grown characteristics when grown in the light have yielded both phytochrome apoprotein and chromophore biosynthetic mutants (Koornneef et al 1980) (Figure 1c). Phytochromobilin is derived from heme, and mutants affected in both committed steps that lead from heme to phytochromobilin have been isolated in Arabidopsis (hyl and hy2), tomato, pea, and Nicotiana plumbaginifolia (pew1 and pew2) (Terry 1997). Mutations affecting steps upstream of heme biosynthesis would affect many other aspects of plant metabolism and are unlikely to survive. Indeed, a third complementation group has been isolated in Arabidopsis (hy6), but due to the strength of the defect, it has proven impossible to maintain viable lines 
(Chory 1992). All the mutants isolated to date are quite leaky and retain some phytochrome activity. Therefore, it is still an open question if higher plants can survive without phytochromes. This issue was addressed recently through a transgenic approach. Animal biliverdin reductase was shown to degrade phytochromobilin in vitro. When biliverdin reductase is overexpressed under the control of the constitutive CaMV35S promoter, phytochrome photoactivity can no longer be detected in transgenic plants. The phenotype of this new class of chromophore mutants is stronger than hyl or hy 2 mutants. Many of the transgenic plants were highly chlorotic and did not survive, suggesting an essential role for phytochromes (Lagarias et al 1997). This is in agreement with the observed lethality of a Nicotiana plumbaginifolia pew1 pew2 double mutant (Kraepiel et al 1994).

Phytochrome apoprotein mutants have been identified in Arabidopsis, tomato, sorghum, and Brassica. In Arabidopsis, screens for long hypocotyl mutants in white and far-red light have yielded phyB and phyA mutants, respectively (Figure 1c) (Koornneef et al 1980, Dehesh et al 1993, Nagatani et al 1993, Parks \& Quail 1993, Reed et al 1993, Whitelam et al 1993). Recently, phyD mutants also have been described and, as expected from the high homology with phyB, phyD appears to have overlapping functions with phyB (R Sharrock, personal communication). Careful analysis of phyA and $p h y B$ single and double mutants has shown that these two phytochromes affect a number of identical processes in response to different fluences or wavelengths of light (Figure 3 ). Both phyA and phyB affect germination; however, phyA is responsible for the VLF response over a large spectrum, and the photon efficiency relative to wavelength looks very similar to the absorption spectrum of phyA in its redabsorbing form. The LF germination response is red/far-red reversible and can be attributed to phyB (Figure 3a) (Reed et al 1994, Botto et al 1996, Shinomura et al 1996). This work illustrates the ability of phyA to work at very low $\mathrm{Pfr} /$ total phytochrome ratios in contrast to phyB, which requires higher Pfr/total phytochrome values. A model explaining the different working mechanisms of phyA and phyB has been proposed (Furuya \& Schäfer 1996).

Expression of the nuclear photosynthetic gene $L H C B$ in response to red light depends on both phyA and phyB (Reed et al 1994). A more detailed study has demonstrated that this biphasic fluence response is the sum of a very low fluence response (VLFR) controlled by phyA and a phyB low fluence response (LFR). This study also points to a role for an additional phytochrome (C, D or E), as part of the LF far-red reversible response (M Furuya, personal communication). Thus multiple phytochromes contribute to the expression of even a single lightregulated gene such as $L H C B$. In the case of phyA and phyB, they do so via the same cis-regulatory element (S Anderson, K Hanson, J Chory \& S Kay, unpublished data). 


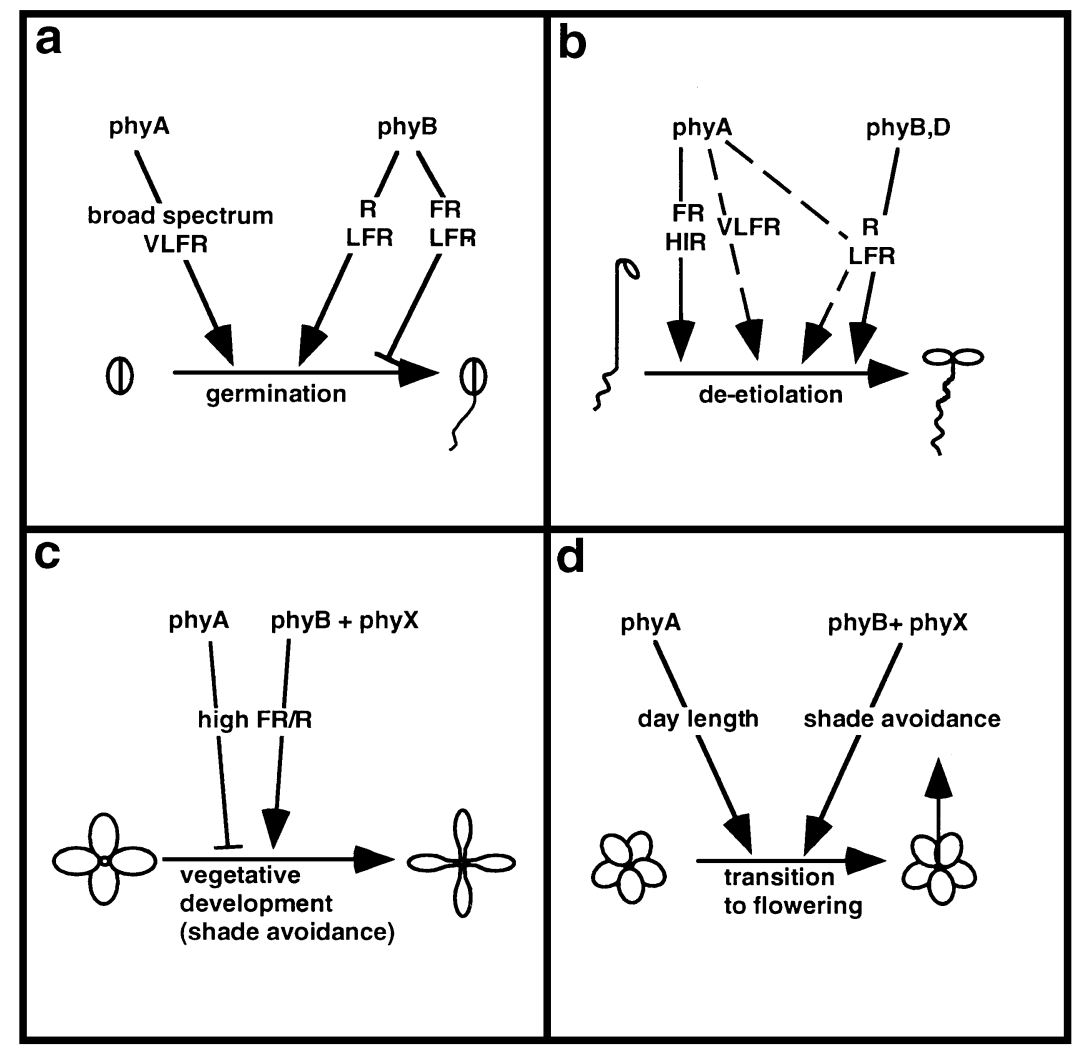

Figure 3 Phytochrome functions throughout the plant's development. (a) The role of phytochrome $\mathrm{A}$ and $\mathrm{B}$ in seed germination; $(b)$ the role of phytochome A, B, and D in de-etiolation; $(c)$ phytochromes influencing vegetative development; $(d)$ the transition to flowering is influenced by phytochromes. Red, R; far-red, FR; very low fluence response, VLFR; low fluence response, LFR; high irradiance response, HIR.

The regulation of hypocotyl elongation by light is an additional example of the complex interplay among photoreceptors. In HI far-red light, phyA is probably the only active photoreceptor, as illustrated by the quasi-complete lack of de-etiolation of null alleles of phyA (Nagatani et al 1993, Whitelam et al 1993). In white or red light, phyB plays a major role, but even null mutants do not have a hypocotyl as long as that of dark-grown plants. The long hypocotyl and reduced cotyledon expansion phenotype of $p h y B$ null mutants is enhanced in double mutants with phyA, phyD, or hy4, which proves that it is the coaction of multiple photoreceptors that senses white light during de-etiolation 
(Neff \& Van Volkenburgh 1994, Chory et al 1996) (Figure 3b). Fluence-dependent inhibition of hypocotyl elongation in response to red light further demonstrates that phyA is responsible for the VLFR and phyB for the LFR (Mazzella et al 1997). Due to its light lability, the contribution of phyA under continuous red or white light is greatly reduced: However, a subtle effect is detected when plants are grown in day/night cycles (Johnson et al 1994).

phyA and phyB can also antagonize the action of each other (Reed et al 1994, Smith 1995). When grown very densely, most plants display a shade-avoidance syndrome in which stems and leaves are elongated and the plants flower early (Figure $3 c$ ). This manifestation of light quality monitoring by phytochromes can be phenocopied by end-of-day far-red (EOD-FR) treatments. phy $B$ mutants look like constitutive shade avoiders and display a reduced response to EOD-FR. In contrast, phyA mutants show a fairly normal shade avoidance response but are impaired in their perception of daylength (Bagnall et al 1995, Casal 1996) (Figure $3 d$ ). An antagonism between the two phytochromes can be detected upon overexpression of phyA in light-grown plants. The resulting transgenic lines no longer display the shade-avoidance response, which apparently is the manifestation of the opposing effects of phyA and phyB in response to elevated levels of far-red light (Smith 1995). This antagonism is minimal in wild-type light-grown plants owing to low phyA levels. phyB mutants flower early under both long and short days, but they still accelerate flowering in response to EOD-FR. This manifestation of shade avoidance is reversible by a subsequent pulse of red light. Shade-avoiding behavior is still present in a phyA phyB double mutant, but absent in hy2 mutants, which strongly suggests a role for another phytochrome (Devlin et al 1996). An additional phytochrome is also responsible for the increased internode elongation in response to EOD-FR. These phenotypes pave the road for the discovery of functions for phytochromes such as phyC and phyE (Devlin et al 1996).

There are some clear functional differences between phyA and phyB. A number of structural differences could account for them, but the underlying mechanism is unknown. We already have discussed the differential light regulation of type I and type II phytochromes at the whole plant level. A detailed analysis of the tissue distribution throughout the development of Arabidopsis shows that the $P H Y A$ and $P H Y B$ promoters are expressed in an almost identical pattern, with the exception of pollen where only PHYB is expressed (Somers \& Quail 1995). At the subcellular level, however, there is a striking difference. phyA is always cytoplasmic, whereas phyB becomes nuclear in response to light (Sakamoto \& Nagatani 1996). This recent finding could account for at least part of their distinct properties. A search for interacting partners that are common or specific for different phytochromes will allow us to test for the presence of unique or separate signaling pathways. 


\section{PHYTOCHROME AND CRYPTOCHROME SIGNAL TRANSDUCTION}

\section{Positively Acting Factors}

Our knowledge of the structure and mechanism by which phytochromes and cryptochromes perceive light has advanced tremendously in recent years (Quail et al 1995, Ahmad \& Cashmore 1996a). Despite this detailed knowledge, we still know very little about the mechanisms of light signaling and the complexity of the signaling network (Elich \& Chory 1994, Chory et al 1996). Genetic screens for long hypocotyl mutants have identified a number of light-insensitive mutants (Table 1). Many of these mutants define phytochrome apoproteins, chromophore biosynthesis enzymes, or cryptochrome, as described above. However, a few loci may play a role in downstream events from the photoreceptors. elg and hy5 mutants have a long hypocotyl under all light conditions tested (Koornneef et al 1980, Halliday et al 1996) and could act downstream in the light signaling network after the integration of signals from multiple photoreceptors. elf 3 mutants seem specifically impaired in blue and green light-mediated inhibition of hypocotyl elongation. Moreover, their daylength-dependent control of reproductive development is impaired, and they lack normal circadian rhythms when assayed under constant light. These data suggest that ELF3 acts specifically downstream of blue light receptors and not downstream of phytochromes (Zagotta et al 1996).

Several mutants appear to be defective in phytochrome signaling. fhyl and fhy3 mutants were isolated on the basis of their insensitivity to far-red light (Whitelam et al 1993). They respond normally to light of other wavelengths, suggesting that these mutants may be impaired specifically in phyA signaling. A more detailed analysis of $f h y l$ mutants has revealed that they are defective in a subset of phyA functions, suggesting that FHY1 does indeed act downstream in a phyA signal transduction pathway (Johnson et al 1994, Barnes et al 1996a,b). cr88 mutants fail to properly regulate the expression of several genes in response to light, are slow greening, and have a long hypocotyl when grown in red light (Lin \& Cheng 1997). Some early flowering mutants described recently-pefl, pef 2 , and pef3-display a long hypocotyl phenotype when grown in red, but not blue or UV-A, light. Unlike pef2 and pef3, pef1 mutants are also blind to far-red. pefl does not appear to be a phytochrome apoprotein or chromophore mutant, which suggests that it might be the first identified positive regulator common to both phyA and phyB signaling. pef 2 and pef3 could be mutant alleles of phyC, phyD, or phyE (Ahmad \& Cashmore 1996b). The mapping of these genes should clarify the situation in the near future.

Screens for second site suppressors have been instrumental in deciphering complex signal transduction pathways in Drosophila, C. elegans, and yeast. 
Table 1 Arabidopsis photomorphogenesis mutants

\begin{tabular}{|c|c|c|c|}
\hline Mutant & Seedling phenotype ${ }^{a}$ & Gene product & Reference \\
\hline hyl & $\begin{array}{l}\text { Long hypocotyl, reduced } \\
\text { cotyledons in W/R/FR }\end{array}$ & $\begin{array}{l}\text { Chromophore } \\
\text { biosynthesis } \\
\text { heme oxygenase? }\end{array}$ & Koornneef et al 1980 \\
\hline hy 2 & Same as $h y 1$ & $\begin{array}{l}\text { Chromophore } \\
\text { biosynthesis } \\
\text { phytochromo- } \\
\text { bilin synthase? }\end{array}$ & Koornneef et al 1980 \\
\hline hy3/phyB & $\begin{array}{l}\text { Long hypocotyl reduced } \\
\text { cotyledon in W/R }\end{array}$ & Phytochrome B & $\begin{array}{l}\text { Koornneef et al } 1980 \\
\text { Reed et al } 1993\end{array}$ \\
\hline phyD & Enhances $p h y B$ phenotype & Phytochrome D & $\begin{array}{l}\text { R. Sharrock, personal } \\
\text { communication }\end{array}$ \\
\hline phyA & $\begin{array}{l}\text { Long hypocotyl and } \\
\text { no cotyledon expansion } \\
\text { in FR }\end{array}$ & Phytochrome A & $\begin{array}{l}\text { Dehesh et al } 1993 \\
\text { Nagatani et al } 1993 \\
\text { Parks \& Quail } 1993 \\
\text { Whitelam et al } 1993\end{array}$ \\
\hline hy4/cryl & Long hypocotyl in $\mathrm{B} / \mathrm{W}$ & Cryptochrome 1 & $\begin{array}{l}\text { Koorneef et al } 1980 \\
\text { Ahmad \& Cashmore } 1993\end{array}$ \\
\hline cry $2 ?$ & $\begin{array}{l}\text { Reduced cotyledon } \\
\text { expansion in B }\end{array}$ & Cryptochrome $2 ?$ & $\begin{array}{l}\text { C Lin, personal } \\
\text { communication }\end{array}$ \\
\hline JK224/nph1 & Phototropism defect & $\begin{array}{l}\text { Phosphorylation } \\
\text { of } 120-\mathrm{kDa} \\
\text { protein, receptor? }\end{array}$ & $\begin{array}{l}\text { Khurana et al } 1989 \\
\text { Liscum \& Briggs } 1995\end{array}$ \\
\hline hy 5 & $\begin{array}{l}\text { Long hypocotyl in } \\
\text { B/R/FR/W }\end{array}$ & $\begin{array}{l}\text { bZIP transcription } \\
\text { factor }\end{array}$ & $\begin{array}{l}\text { Koornneef et al 1980; K } \\
\text { Okada, personal } \\
\text { communication }\end{array}$ \\
\hline elg & $\begin{array}{l}\text { Long hypocotyl in } \\
\text { B/R/FR/W }\end{array}$ & $?$ & Halliday et al 1996 \\
\hline fhyl & Long hypocotyl in FR & $?$ & Whitelam et al 1993 \\
\hline fhy3 & Long hypocotyl in FR & $?$ & Whitelam et al 1993 \\
\hline $\operatorname{cr} 88$ & Long hypocotyl in R/W & $?$ & Lin \& Cheng 1997 \\
\hline pefl & Long hypocotyl in R/FR & $?$ & Ahmad \& Cashmore 1996b \\
\hline pef2 & Long hypocotyl in $\mathrm{R}$ & $?$ & Ahmad \& Cashmore 1996b \\
\hline pef3 & Same as pef2 & $?$ & Ahmad \& Cashmore 1996b \\
\hline elf 3 & Long hypocotyl in B/W & $?$ & Zagotta et al 1996 \\
\hline$n p h 2$ & Phototropic mutant & $?$ & Liscum \& Briggs 1995 \\
\hline$n p h 3$ & Same as $n p h 2$ & $?$ & $\begin{array}{l}\text { Liscum \& Briggs } 1995 \\
\text { Khurana et al } 1989\end{array}$ \\
\hline
\end{tabular}


Table 1 Continued

\begin{tabular}{|c|c|c|c|}
\hline Mutant & Seedling phenotype ${ }^{a}$ & Gene product & Reference \\
\hline$n p h 4$ & $\begin{array}{l}\text { Phototropic and } \\
\text { gravitropic mutant }\end{array}$ & $?$ & Liscum \& Briggs 1995 \\
\hline shylD & $\begin{array}{l}\text { Partial de-etiolation in } \\
\text { dark (dominant mutant) }\end{array}$ & $?$ & Kim et al 1996 \\
\hline $\operatorname{shy} 2 D$ & $\begin{array}{l}\text { Partial de-etiolation } \\
\text { in the dark } \\
\text { (dominant mutant) }\end{array}$ & $?$ & Kim et al 1996 \\
\hline cuel-9 & $\begin{array}{l}\text { Underexpression } \\
\text { of LHCB in the light }\end{array}$ & $?$ & $\begin{array}{l}\text { Li et al 1995; } \\
\text { E Lopez \& J Chory, } \\
\text { unpublished results }\end{array}$ \\
\hline $\operatorname{det} 1$ & $\begin{array}{l}\text { Light-independent } \\
\text { gene expression, } \\
\text { leaf and chloroplast } \\
\text { development }\end{array}$ & Nuclear protein & Pepper et al 1994 \\
\hline copl & Same as det 1 & Nuclear protein & Deng et al 1992 \\
\hline $\operatorname{cop} 9$ & Same as det 1 & Nuclear protein & Wei \& Deng 1992 \\
\hline fus6 & Same as det 1 & Nuclear protein & Castle \& Meinke 1994 \\
\hline $\begin{array}{l}\text { fus } 4,5,8,9 \\
\quad 11,12\end{array}$ & Same as det 1 & $?$ & Miséra et al 1994 \\
\hline $\operatorname{det} 2$ & $\begin{array}{l}\text { Light-independent } \\
\text { gene expression } \\
\text { and leaf development }\end{array}$ & Biosynthesis of BR & Li et al 1996 \\
\hline$c p d$ & Same as det 2 & Biosynthesis of BR & Szekeres et al 1996 \\
\hline $\operatorname{dim}$ & Same as $\operatorname{det} 2$ & Biosynthesis of BR & $\begin{array}{l}\text { Takahashi et al 1995, } \\
\text { Szekeres et al } 1996\end{array}$ \\
\hline bri/cbb2 & $\begin{array}{l}\text { Same as det } 2 \text { but not } \\
\text { rescued by BR application }\end{array}$ & $?$ & $\begin{array}{l}\text { Clouse et al } 1996 \\
\text { Kauschmann et al } 1996\end{array}$ \\
\hline $\operatorname{det} 3$ & $\begin{array}{l}\text { Light independent leaf } \\
\text { development }\end{array}$ & $?$ & Cabrera y Poch et al 1993 \\
\hline сор2/amp & $\begin{array}{l}\text { Light-independent } \\
\text { cotyledon opening }\end{array}$ & $?$ & $\begin{array}{l}\text { Chaudhury et al } 1993 \text {, } \\
\text { Hou et al } 1993\end{array}$ \\
\hline cop3/hlsl & Same as cop2 & $N$-acetyltransferase & Lehman et al 1996 \\
\hline cop4 & $\begin{array}{l}\text { Same as cop2 and } \\
\text { gravitropic defect }\end{array}$ & $?$ & Hou et al 1993 \\
\hline sabre & Cell elongation defect & Novel protein & Aeschbacher et al 1995 \\
\hline prc & $\begin{array}{l}\text { Dark specific hypocotyl } \\
\text { Elongation defect }\end{array}$ & $?$ & Desnos et al 1996 \\
\hline $\operatorname{doc} 1-3$ & $\begin{array}{l}\text { Overexpression of } L H C B \\
\text { in the dark }\end{array}$ & $?$ & Li et al 1994 \\
\hline
\end{tabular}

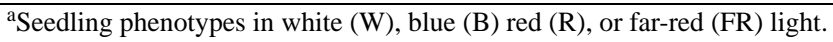


The first example of such a screen applied to Arabidopsis photomorphogenesis has uncovered two dominant mutations, shyl and shy2, that partially rescue the chromophore-deficient mutant hy2 (Kim et al 1996). In either the presence or absence of the chromophore mutation, shyl and shy 2 are partially de-etiolated in the dark. shyl mutants rescue hy 2 more efficiently in red than in far-red light, suggesting that shyl is more directly implicated in phyB than phyA signaling. Other hy2 phenotypes, such as early flowering and low chlorophyll content, are also partially suppressed by shyl and shy2 (Kim et al 1996). Molecular characterization of these mutants and the search for allele-specific suppressors of photoreceptor mutants should lead to a clearer picture of the early events in light signaling.

A complementary approach has been to define second messengers of light signaling by pharmacological and biochemical studies. Biochemical complementation of a tomato chromophore aurea mutation by microinjection of purified or recombinant phytochrome has been used successfully (Barnes et al 1997). Microinjection of various signaling intermediates and inhibitors has led to the following model for phytochrome action. Phytochrome signals through heterotrimeric $\mathrm{G}$ proteins, followed by one of three branched pathways: one in which cGMP is an effector, one that requires $\mathrm{Ca}^{2+}$ and calmodulin, and a third that relies on both cGMP and $\mathrm{Ca}^{2+} / \mathrm{calmodulin}$. There appears to be reciprocal negative control among these pathways, i.e. overactivation of one occurs at the expense of the other. At the present time, no clear link between the genetic and biochemical studies exists. Molecular identification of an element implicated by both types of studies would represent a big step forward.

\section{Repressors of Photomorphogenesis}

Several laboratories have identified a large number of recessive mutants that display some or most aspects of de-etiolation when grown in the dark (Table 1). The most straightforward explanation for such a phenotype is that de-etiolation in the dark is actively repressed by these genes. Upon closer phenotypic examination, these mutants can be classified into at least three groups that we deal with separately below (reviewed in Chory et al 1996, von Arnim \& Deng 1996, Wei \& Deng 1996).

PLEIOTROPIC MUTATIONS Mutations in ten genes, variously called DET, COP, $F U S$, and $E M B$, have been identified that allow dark-grown Arabidopsis seedlings to develop as light-grown plants (Table 1). When grown in the dark, these mutants have short hypocotyls, open apical hooks, expanded cotyledons, partially developed chloroplasts, and they express multiple nuclear and plastidencoded light-regulated genes (Figure 1d). In the light, strong alleles die as seedlings, whereas in the few cases for which there are weak alleles, the mutants are small, have decreased apical dominance and fertility, and express 
light-regulated genes in inappropriate cell types. These loci have been given up to four different names by the different laboratories working on them. For convenience and based on historical consideration, we call these loci by the following names: DET1, COP1, COP9, FUS4, FUS5, FUS6, FUS8, FUS9, FUS11, and FUS12 (Chory et al 1996).

The essential nature of these genes very early in development has prompted some debate about their direct implication in photomorphogenesis (Mayer et al 1996). There are several lines of evidence supporting the notion that at least some of these genes have an important role in light signaling (which does not mean that this is their sole function). For instance, a careful analysis of an allelic series of detl and copl mutations has shown that stress-related accumulation of anthocyanin and de-etiolation in the dark can be genetically separated. These results suggest that de-etiolation in the dark is not simply the reflection of a stressed plant. Other genetic arguments have been made for the importance of DET1 and COP1 in photomorphogenesis. In one study, several new hy 5 alleles were identified in a suppressor screen of a weak det 1 mutation (Pepper \& Chory 1997). Genetic interactions between copl and hy5 have also been reported (Ang $\&$ Deng 1994). These data link a positively acting regulator to the repressors of de-etiolation. In addition, double-mutant analysis shows that these mutations are epistatic to photoreceptor mutations for most phenotypic traits (Chory 1992, Chory et al 1996). Overexpression of COP1 in Arabidopsis results in plants with reduced sensitivity to light and no other obvious developmental defect (McNellis et al 1994).

The primary sequence of the cloned DET, COP, and FUS proteins has not been very informative, and despite considerable effort we can only speculate about their function. DET1, COP1, COP9, and FUS6 can all localize to the nucleus; none appears to bind DNA directly (Pepper et al 1994, von Arnim $\&$ Deng 1994, Chamovitz et al 1996, Staub et al 1996). Based on the mutant phenotypes and the available molecular characterization, it appears that these genes repress transcription of light-induced genes. Several models of how this could be accomplished have been discussed elsewhere (Chory et al 1996). COP9 and FUS6 are part of an abundant 550-kDa protein complex composed of approximately a dozen proteins (Chamovitz et al 1996, Staub et al 1996). The absence of this complex in fus 8 mutants suggests that this gene product is part of the complex or is essential for its assembly. There is no evidence for assembly of DET1 and COP1 with this structure. The localization of COP1 appears to be influenced by light (von Arnim \& Deng 1994). COP1 is nuclear in the dark and becomes cytoplasmic after prolonged periods in the light. These results have been interpreted as follows: Upon illumination with light, the COP1 repressor is relocalized to the cytoplasm, allowing the various light-induced genes to be expressed. This simple model does not explain the complexity of the copl phenotype. For example, why do copl mutants have a strong phenotype in the 
light? Also, the kinetics of relocalization are too slow to account for the kinetics of light-induced gene induction. Several other genes of this class remain to be isolated. It will be interesting to see if some of them will be components of the $550-\mathrm{kDa}$ complex and if any will be shown to bind DNA directly.

The switch from dark- to light-grown development has no obvious counterpart in animal development. The cloning and sequencing of $C O P 1, C O P 9$, FUS6, and DETI have, however, revealed potential animal homologues of these genes (Chamovitz \& Deng 1995). Gpa1, a human protein that is almost 50\% identical to FUS6, has been analyzed in some detail. A truncated form of Gpa1 was isolated as a suppressor of constitutive $\mathrm{G} \beta \gamma$ signaling in yeast and fulllength Gpa1 inhibits ras and MAP kinase signaling when overexpressed in NIH 3T3 cells (Spain et al 1996). The mechanism by which this human counterpart of FUS6 inhibits G protein signaling is unknown, but it is exciting to find that Gpa1 inhibits a signaling cascade that has been implicated in phytochrome signal transduction.

MUTANTS THAT AFFECT A SUBSET OF DE-ETIOLATION RESPONSES There are a number of additional loci that affect only certain aspects of etiolation in the dark, but our present knowledge does not allow us to classify them precisely. cop4 mutants have a gravitropic defect, and sabre and procuste ( $p r c$ ) affect cell elongation (Hou et al 1993, Aeschbacher et al 1995, Desnos et al 1996). prc mutants affect hypocotyl elongation in the dark exclusively, revealing an additional level of complexity. Mutant prc plants have abnormal root cells, but their aerial parts are normal. This suggests that the hypocotyl, which is a poorly differentiated organ, can adopt two fates depending on its environment. During the etiolated phase, the hypocotyl grows in the soil and adopts a rootlike structure. When the hypocotyl emerges into the light, elongation growth is slowed and, due to a new set of physical constraints, it becomes shoot-like. phyb prc double mutants have cell elongation defects in red light, suggesting that phyb is not required solely to reduce cell elongation in response to light, but also plays an important role for this cell fate transition (Desnos et al 1996).

PLANT HORMONE MUTANTS AND SIGNAL INTEGRATION A third class of mutants that de-etiolate partially in the dark is now known to be involved in plant hormone synthesis, homeostasis, or perception. DET2, CPD, and DIM are enzymes of the biosynthetic pathway leading to the plant steroid hormone, brassinolide (BR) (Table 1). det2, cpd, and dim mutants are rescued by BR application (Takahashi et al 1995, Li et al 1996, Szekeres et al 1996). A mutant with a phenotype very similar to these biosynthetic mutants is particularly interesting because it is not rescued by BR applications and may define a BR receptor (Clouse et al 1996). det3 mutants also fail to respond to BR application, but 
their phenotype is very distinct from BR mutants (Cabrera y Poch et al 1993, Szekeres et al 1996). The phenotypes of the BR biosynthetic mutants indicate a role for BRs in the control of cell elongation, the expression of photoregulated genes, and the promotion of apical dominance and leaf senescence-all responses know to be regulated by light. How light might interact with brassinolide biosynthesis or response pathways is not known. Light might alter the content of BRs in an organ responding to light. Alternatively, light might impact seedling development by altering the responsivity of cells to brassinolide. To understand the mechanism by which light might alter the sensitivity of cells to BR, it will be necessary to identify the brassinolide receptor. For a more detailed discussion about BRs and light signal transduction, see a recent review (Chory \& Li 1997).

Auxin, gibberellins (GA), cytokinins, and ethylene have also been reported to affect photomorphogenesis. ampl/cop2, a mutant that has increased cytokinin content, develops as a light-grown plant in the dark (Chaudhury et al 1993, Hou et al 1993). Some dark-grown mutants do not make an apical hook and have been referred to as hookless (hls). hls1 (also isolated as cop3) mutants demonstrate the potential role for auxin and ethylene in de-etiolation, as molecular and genetic data suggest that HLS1 controls differential growth (the mechanism that allows bending of plant organs) by regulating auxin activity in response to ethylene (Lehman et al 1996). The interplay between light and gibberellins has also been suggested in numerous plant species. In some plants, the mechanism involves down-regulation of GA biosynthesis by light, but in most cases, there appears to be a phytochrome-dependent decrease of responsiveness to GAs. These studies clearly hint at the interplay between light and hormonal signals (reviewed in Chory \& Li 1997).

\section{Light Signaling and Circadian Rhythms}

The circadian clock is another good example of signal integration. Many essential photosynthetic genes are light regulated at the transcriptional level. However, it would be much more efficient for the plant to anticipate day/night cycles. The circadian clock plays this essential energy-saving role. This was very elegantly demonstrated for $\angle H C B$ gene expression for which light-regulation is inhibited by the clock in anticipation of dusk and its role alleviated at the end of the night in order to transcribe $L H C B$ before dawn (Millar \& Kay 1996). Genetic dissection of the circadian clock has shown that a number of mutants affecting circadian timing also have a photomorphogenetic defect, thus demonstrating the tight link between these two phenomena (Anderson \& Kay 1996).

\section{Inappropriate Gene Expression Mutants}

To identify downstream elements of light signal transduction, several screens have identified mutants that inappropriately express tightly regulated genes. By 
using the $\angle H C B$ (previously called $C A B$ ) promoter driving appropriate reporter genes, mutations in three genes that overexpress $L H C B$ in the dark (doc: dark $o$ verexpresser of $c \mathrm{ab}$ ) or in nine genes that underexpress $L H C B$ in the light (cue: cab under expressors) have been identified in our laboratory (Li et al 1994, 1995). The doc mutants are recessive, suggesting they are negative regulators of photomorphogenesis. These mutations are much less pleiotropic than det, cop, fus, or emb mutations because they do not alter the morphology of the etiolated seedling. Epistasis analysis suggests that DOC1 acts downstream from DET1 in light signaling ( $\mathrm{Li}$ et al 1994). Little is known about the cue mutants; however, new hyl and $p h y B$ alleles have been isolated as cue mutants, strongly suggesting that this screen will yield some important positive regulators of phytochrome signal transduction.

\section{DOWNSTREAM TARGETS OF LIGHT SIGNAL TRANSDUCTION}

The best characterized targets of light signal transduction are numerous nuclear genes that are either activated or repressed in response to light (Terzaghi et al 1995). An obviously attractive route to understand light signaling is to start with a tightly regulated gene and define the cis-acting elements necessary for its regulation. This has been a topic of intense study. The major problem thus far is that numerous elements appear to be necessary for light-regulated gene expression. It is still unclear if any one is sufficient to provide robust light regulation. On the contrary, it appears, as for many biological systems, that the combination of multiple elements in a given context provides the specificity (Menkens et al 1995). A second hurdle has been the identification of transcription factors that play a role in light signaling in vivo. A recent report suggests that this has been achieved for one factor, CCA1, which binds a cis-element in an $L H C B$ promoter (Wang et al 1997).

Light responses that do not require transcriptional regulation are even less well understood. Numerous light responses occur within seconds of photoreceptor excitation, strongly suggesting that they do not require de novo protein synthesis. Inhibition of hypocotyl elongation and transient depolarization of the plasma membrane are good examples (Kendrick \& Kronenberg 1994). It is possible that light signal transduction branches very rapidly, with a subset of responses controlled at the level of light-regulated transcription. Other rapid responses might occur at the level of the cytoskeleton or the secretion machinery to affect cell wall composition and hence the capacity of the cell to elongate. This is analogous to the situation in yeasts that are responding to mating pheromones. 


\section{CONCLUSIONS}

Genetic studies indicate that light responses are not simply endpoints of linear signal transduction pathways but result from the integration of information from a network of interacting signaling components. The signaling components include the photoreceptors themselves, as well as positive and negative regulatory elements that act downstream from these photoreceptors. The data suggest that a small number of negative signaling components regulates a multitude of responses by co-opting a larger number of specific regulatory molecules. The identification of these molecules and how they interact with each other should aid our understanding of how organisms perceive and respond to signals from their environment.

\section{ACKNOWLEDGMENTS}

We thank Michael Neff and Cindy Doane for their help with the figures. We thank M Neff and T Elich for comments; and M Furuya, JC Lagarias, C Lin, K Okada, R Sharrock, and E Tobin for sharing unpublished results. CF is supported by fellowships from the Swiss National Science Fund and the International Human Frontiers Science Program Organization. Work on photomorphogenesis in our laboratory is supported by grants from the NIH, NSF, DOE, and USDA, and by the Samuel Roberts Noble Foundation (Ardmore, OK).

Visit the Annual Reviews home page at http://www.annurev.org.

\section{Literature Cited}

Aeschbacher RA, Hauser M-T, Feldman KA, Benfey PN. 1995. The SABRE gene is required for normal cell expansion in Arabidopsis. Genes Dev. 9:330-40

Ahmad M, Cashmore AR. 1993. HY4 gene of A. thaliana encodes a protein with characteristics of a blue-light photoreceptor. Nature 366:162-66

Ahmad M, Cashmore AR. 1996a. Seeing blue: the discovery of cryptochrome. Plant Mol. Biol. 30:851-61

Ahmad M, Cashmore AR. 1996b. The pef mutants of Arabidopsis thaliana define lesions early in the phytochrome signaling pathway. Plant J. 10:1103-10

Ahmad M, Lin C, Cashmore AR. 1995. Mutations throughout an Arabidopsis blue-light photoreceptor impair blue-light-responsive anthocyanin accumulation and inhibition of hypocotyl elongation. Plant J. 8:653-58

Andel F III, Lagarias JC, Mathies RA. 1996. Resonance raman analysis of chromophore structure in the lumi-R photoproduct. Biochemistry 35:15997-6008

Anderson SL, Kay SA. 1996. Illuminating the mechanism of the circadian clock in plants. Trends Plant Sci. 1:51-57

Ang L-H, Deng X-W. 1994. Regulatory hierarchy of photomorphogenic loci: genetic evidence for direct interaction between COP1 and HY5 in controlling Arabidopsis seedling development. Plant Cell 6:613-28

Bagnall DJ, King RW, Whitelam GC, Boylan MT, Wagner D, Quail PH. 1995. Flowering responses to altered expression of phytochrome in mutants and transgenic lines of Arabidopsis thaliana (L.) Heynh. Plant Physiol. 108:1495-503

Barnes SA, McGrath RB, Chua N-H. 1997. Light signal transduction in plants. Trends Cell Biol. 7:21-26

Barnes SA, Nishizawa NK, Quaggio RB, Whitelam GC, Chua N-H. 1996a. Farred light blocks greening of Arabidopsis 
seedlings via a phytochrome A-mediated change in plastic development. Plant Cell 8:601-15

Barnes SA, Quaggio RB, Whitelam GC, Chua N-H. 1996b. fhyl defines a branch point in phytochrome A signal transduction pathways for gene expression. Plant J. 10:1155-61

Botto JF, Sanchez RA, Whitelam GC, Casal JJ. 1996. Phytochrome A mediates the promotion of seed germination by very low fluences of light and canopy shade light in Arabidopsis. Plant Physiol. 110:439-44

Boylan M, Douglas N, Quail PH. 1994. Dominant negative suppression of Arabidopsis photoresponses by mutant phytochrome A sequences identifies spatially discrete regulatory domains in the photoreceptor. Plant Cell 6:449-60

Bradley JM, Murphy GP, Whitelam GC, Harberd NP. 1996. Identification of phytochrome $\mathrm{B}$ amino acid residues mutated in three new phyB mutants of Arabidopsis thaliana. J. Exp. Bot. 47:1449-55

Butler WL, Norris KH, Siegelman HW, Hendricks SB. 1959. Detection, assay, and preliminary purification of the pigment controlling photoresponsive development of plants. Proc. Natl. Acad. Sci. USA 45:703-8

Cabrera y Poch HL, Peto CA, Chory J. 1993. A mutation in the Arabidopsis DET3 gene uncouples photoregulated leaf development from gene expression and chloroplast biogenesis. Plant J. 4:671-82

Casal JJ. 1996. Phytochrome A enhances the promotion of hypocotyl growth caused by reductions in levels of phytochrome $B$ in its farred-light-absorbing form in light-grown Arabidopsis thaliana. Plant Physiol. 112:965-73

Castle LA, Meinke DW. 1994. A FUSCA gene of Arabidopsis encodes a novel protein essential for plant development. Plant Cell 6:25-41

Chamovitz DA, Deng X-W. 1995. The novel components of the Arabidopsis light signaling pathway may define a group of general developmental regulators shared by both animal and plant kingdoms. Cell 82:353-54

Chamovitz DA, Wei N, Osterlund MT, von Arnim AG, Staub JM, et al. 1996. The COP9 complex, a novel multisubunit nuclear regulator involved in light control of a plant developmental switch. Cell 86:115-21

Chaudhury AM, Letham S, Craig S, Dennis ES. 1993. amp 1 - a mutant with high cytokinin levels and altered embryonic pattern, faster vegetative growth, constitutive photomorphogenesis and precocious flowering. Plant J. 4:907-16

Cherry JR, Hondred D, Walker JM, Keller JM, Hershey HP, Vierstra RD. 1993. Carboxyterminal deletion analysis of oat phytochrome A reveals the presence of separate domains required for structure and biological activity. Plant Cell 5:565-75

Cherry JR, Hondred D, Walker JM, Vierstra RD. 1992. Phytochrome requires the 6-kDa Nterminal domain for full biological activity. Proc. Natl. Acad. Sci. USA 89:5039-43

Chory J. 1992. A genetic model for lightregulated seedling development in Arabidopsis. Development 115:337-54

Chory J, Chatterjee M, Cook RK, Elich T, Fankhauser C, et al. 1996. From seed germination to flowering, light controls plant development via the pigment phytochrome. Proc. Natl. Acad. Sci. USA 93:12066-71

Chory J, Li J. 1997. Gibberellins, brassinosteroids and light-regulated development. Plant Cell Environ. In press

Christie JM, Jenkins GI. 1996. Distinct UV-B and UV-A/blue light signal transduction pathways induce chalcone synthase gene expression in Arabidopsis cells. Plant Cell 8:155567

Christopher DA, Mullet JE. 1994. Separate photosensory pathways co-regulated blue light/ultraviolet-A-activated $p s b \mathrm{D}-p s b \mathrm{C}$ transcription and light-induced D2 and CP43 degradation in barley (Hordeum vulgare) chloroplasts. Plant Physiol. 104:1119-29

Clouse S, Langford M, McMorris TC. 1996. A brassinosteroid-insensitive mutant in Arabidopsis thaliana exhibits multiple defects in growth and development. Plant Physiol. 111:671-78

Dehesh K, Franci C, Parks BM, Seeley KA, Short TW, et al. 1993. Arabidopsis HY8 locus encodes phytochrome A. Plant Cell 5:108188

Deng X-W, Matsui M, Wei N, Wagner D, Chu AM, et al. 1992. COP1, an Arabidopsis regulatory gene, encodes a protein with both a zinc-binding motif and a $\mathrm{G} \beta$ homologous domain. Cell 71:791-801

Desnos T, Orbovic V, Bellini C, Kronenberger J, Caboche M, et al. 1996. Procuste $1 \mathrm{mu}-$ tants identify two distinct genetic pathways controlling hypocotyl cell elongation, respectively in dark- and light-grown Arabidopsis seedlings. Development 122:683-93

Devlin PF, Halliday KJ, Harberd NP, Whitelam GC. 1996. The rosette habit of Arabidopsis thaliana is dependent upon phytochrome action: novel phytochromes control internode elongation and flowering time. Plant J. 10:1127-34

Elich TD, Chory J. 1994. Initial events in phytochrome signalling: still in the dark. Plant Mol. Biol. 26:1315-27

Firn RD 1994. Phototropism. In Photomorphogenesis in Plants, ed. RE Kendrick, GHM Kronenberg, pp. 659-81. Dordrecht, The Netherlands: Kluwer. 2nd ed. 
Fuglevand G, Jackson JA, Jenkins GI. 1996. UV-B, UV-A, and blue light signal transduction pathways interact synergistically to regulate chalcone synthase gene expression in Arabidopsis. Plant Cell 8:2347-57

Furuya M, Schäfer E. 1996. Photoperception and signalling of induction reactions by different phytochromes. Trends Plant Sci. $1: 301-7$

Halliday K, Devlin PF, Whitelam GC, Hanhart C, Koornneef M. 1996. The ELONGATED gene of Arabidopsis acts independently of light and gibberellins in the control of elongation growth. Plant J. 9:305-12

Hou Y, von Arnim A, Deng X-W. 1993. A new class of Arabiodpsis constitutive photomorphogenic genes involved in regulating cotyledon development. Plant Cell 5:329-39

Hughes J, Lamparter T, Mittmann F, Hartmann E, Gartner W, et al. 1997. A procaryotic phytochrome (scientific correspondence). Nature 386:663

Johnson E, Bradley M, Harberd NP, Whitelam GC. 1994. Photoresponses of light-grown phyA mutants of Arabidopsis: phytochrome $\mathrm{A}$ is required for the perception of daylength extensions. Plant Physiol. 105:141-49

Jones AM, Edgerton MD. 1994. The anatomy of phytochrome, a unique photoreceptor in plants. Sem. Cell Biol. 5:295-302

Jordan ET, Cherry JR, Walker JM, Vierstra RD. 1996. The amino-terminus of phytochrome A contains two distinct functional domains. Plant J. 9:243-57

Kauschmann A, Jessop A, Koncz C, Szekeres M, Willmitzer L, Altmann T. 1996. Genetic evidence for an essential role of brassinosteroids in plant development. Plant J. 9:70113

Kehoe DM, Grossman AR. 1996. Sensor of chromatic adaptation is similar to phytochrome and ethylene receptors. Science 273:1409-12

Kendrick RE, Kronenberg GHM, eds. 1994. Photomorphogenesis in Plants. Dordrecht, The Netherlands: Kluwer. 2nd ed.

Khurana JP, Ren Z, Steinitz B, Parks B, Best TR, Poff KL. 1989. Mutants of Arabidopsis thaliana with decreased amplitude in their phototropic response. Plant Physiol. 91:68589

Kim BC, Soh MS, Kang BJ, Furuya M, Nam HG. 1996. Two dominant photomorphogenic mutations of Arabidopsis thaliana identified as suppressor mutations of hy2. Plant J. 9:441-56

Konjevic R, Steinitz B, Poff KL. 1989. Dependence of the phototropic response of Arabidopsis thaliana on fluence rate and wavelength. Proc. Natl. Acad. Sci. USA 86:9876-80
Koornneef M, Rolff E, Spruit CJP. 1980. Genetic control of light-inhibited hypocotyl elongation in Arabidopsis thaliana (L.). Heynh Z. Pflanzenphysiol. 100S:147-60

Kraepiel Y, Jullien M, Cordonnier-Pratt MM, Pratt L. 1994. Identification of two loci involved in phytochrome expression in Nicotiana plumbaginifolia and lethality of the corresponding double mutant. Mol. Gen. Genet. 242:559-65

Kunkel T, Neuhaus G, Batschauer A, Chua NH, Schäfer E. 1996. Functional analysis of yeast-derived phytochrome A and B phycocyanobilin adducts. Plant J. 10:625-36

Lagarias DM, Crepeau MW, Maines MD, Lagarias JC. 1997. Regulation of photomorphogenesis by expression of mammalian biliverdin reductase in transgenic Arabidopsis plants. Plant Cell 9:675-88

Lagarias DM, Wu S-H, Lagarias JC. 1995. Atypical phytochrome gene structure in the green alga Mesotaenium caldariorum. Plant Mol. Biol. 29:1127-42

Lehman A, Black R, Ecker JR. 1996. HOOKLESS1, an ethylene response gene, is required for differential cell elongation in the Arabidopsis hypocotyl. Cell 85:183-94

Li H-m, Altschmied L, Chory J. 1994. Arabidopsis mutants define downstream branches in the phototransduction pathway. Genes Dev. 8:339-49

Li H-m, Culligan K, Dixon RA, Chory J. 1995. CUE1: a mesophyll cell-specific positive regulator of light-controlled gene expression in Arabidopsis. Plant Cell 7:1599-610

Li J, Nagpal P, Vitart V, McMorris TC, Chory J. 1996. A role for brassinosteroids in lightdependent development of Arabidopsis. Science 272:398-401

Lin C, Ahmad M, Cashmore AR. 1996. Arabidopsis cryptochrome 1 is a soluble protein mediating blue light-dependent regulation of plant growth and development. Plant J. 10:893-902

Lin C, Ahmad M, Gordon D, Cashmore AR. 1995a. Expression of an Arabidopsis cryptochrome gene in transgenic tobacco results in hypersensitivity of blue, UVA, and green light. Proc. Natl. Acad. Sci. USA 92:8423-27

Lin C, Robertson DE, Ahmad M, Raibekas AA, Jorns MS, et al. 1995b. Association of flavin adenine dinucleotide with the Arabidopsis blue light receptor CRY1. Science 269:96870

Lin Y, Cheng C-L. 1997. A chlorate-resistant mutant defective in the regulation of nitrate reductase gene expression in Arabidopsis defines a new HY locus. Plant Cell 9:21-35

Linden H, Macino G. 1997. White collar 2, a partner in blue-light signal transduction, controlling expression of light-regulated genes in 
Neurospora crassa. EMBO J. 16:98-109

Liscum E, Briggs WR. 1995. Mutations in the NPH1 locus of Arabidopsis disrupt the perception of phototropic stimuli. Plant Cell 7:473-85

Liscum E, Briggs WR. 1996. Mutations of Arabidopsis in potential transduction and response components of the phototropic signaling pathway. Plant Physiol. 112:291-96

Malhotra K, Kim ST, Batschauer A, Dawut L, Sancar A. 1995. Putative blue-light photoreceptors from Arabidopsis thaliana and Sinapis alba with a high-degree of sequence homology to DNA photolyase contain the 2 photolyase cofactors but lack DNA repair activity. Biochemistry 34:6892-99

Mayer R, Raventos D, Chua N-H. 1996. det1, cop1 and cop9 mutations cause inappropriate expression of several gene sets. Plant Cell 8:1951-59

Mazzella MA, Alconada Magliano TM, Casal JJ. 1997. Dual effect of phytochrome A on hypocotyl growth under continuous red light. Plant Cell Environ. 20:261-67

McNellis TW, von Arnim AG, Deng XW. 1994. Overexpression of Arabidopsis COP1 results in partial suppression of light-mediated development: evidence for a light-inactivable repressor of photomorphogenesis. Plant Cell 6:1391-400

Menkens AE, Schindler U, Cashmore AR. 1995. The G-box: a ubiquitous regulatory DNA element in plants bound by the GBF family of bZIP proteins. Trends Biochem. Sci. 20:506-10

Millar AJ, Kay SA. 1996. Integration of circadian and phototransduction pathways in the network controlling $C A B$ gene transcription in Arabidopsis. Proc. Natl. Acad. Sci. USA 93:15491-96

Miséra S, Müller AJ, Weiland-Heidecker U, Jürgens G. 1994. The FUSCA genes of Arabidopsis: negative regulators of light responses. Mol. Gen. Genet. 244:242-52

Nagatani A, Reed RW, Chory J. 1993. Isolation and initial characterization of Arabidopsis mutants that are deficient in phytochrome A. Plant Physiol. 102:269-77

Neff MM, Van Volkenburgh E. 1994. Lightstimulated cotyledon expansion in Arabidopsis seedlings. Plant Physiol. 104:1027-32

Okada K, Shimura Y. 1992. Mutational analysis of root gravitropism and phototropism of Arabidopsis thaliana seedlings. Aust. J. Plant Physiol. 19:439-48

Parks BM, Quail PH. 1993. hy8, a new class of Arabidopsis long hypocotyl mutants deficient in functional phytochrome A. Plant Cell 5:39-48

Parks BM, Quail PH, Hangarter RP. 1996. Phytochrome A regulates red-light induction of phototropic enhancement in Arabidopsis. Plant Physiol. 110:155-62

Pepper A, Chory J. 1997. Extragenic suppressors of the Arabidopsis det1 mutant identify elements of flowering-time and light-response regulatory pathways. Genetics 145:1125-37

Pepper A, Delaney T, Washburn T, Poole D, Chory J. 1994. DET1, a negative regulator of light-mediated development and gene expression in Arabidopsis, encodes a novel nuclearlocalized protein. Cell 78:109-16

Pratt LH. 1995. Phytochromes-differential properties, expression patterns and molecular evolution. Photochem. Photobiol. 61:10-21

Quail PH, Boylan MT, Parks BM, Short TW, Xu Y, Wagner D. 1995. Phytochromes: photosensory perception and signal transduction. Science 268:675-80

Reed JW, Nagatani A, Elich TD, Fagan M, Chory J. 1994. Phytochrome A and phytochrome B have overlapping but distinct functions in Arabidopsis development. Plant Physiol. 104:1039-49

Reed JW, Nagpal P, Poole DS, Furuya M, Chory J. 1993. Mutations in the gene for the red/far red light receptor phytochrome B alter cell elongation and physiological responses throughout Arabidopsis development. Plant Cell 5:147-57

Reymond P, Short TW, Briggs WR. 1992a. Blue light activates a specific protein kinase in higher plants. Plant Physiol. 100:655-61

Reymond P, Short TW, Briggs WR, Poff KL. 1992b. Light-induced phosphorylation of a membrane protein plays an early role in signal transduction for phototropism in Arabidopsis thaliana. Proc. Natl. Acad. Sci. USA 89:4718-21

Robson PRH, Smith H. 1996. Genetic and transgenic evidence that phytochromes $\mathrm{A}$ and $\mathrm{B}$ act to modulate the gravitropic orientation of Arabidopsis thaliana hypocotyls. Plant Physiol. 110:211-16

Sakamoto K, Nagatani A. 1996. Nuclear localization activity of phytochrome B. Plant J. 10:859-68

Sancar A. 1994. Structure and function of DNA photolyase. Biochemistry 33:2-9

Schneider-Poetsch HAW. 1992. Signal transduction by phytochrome: Phytochromes have a module related to the transmitter modules of bacterial sensor proteins. Photochem Photobiol. 56:839-46

Shinomura T, Nagatani A, Hanzawa H, Kubota M, Watanabe M, Furuya M. 1996. Action spectra for phytochrome A- and B-specific photoinduction of seed germination in Arabidopsis thaliana. Proc. Natl. Acad. Sci. USA 93:8129-33

Short TW, Briggs WR. 1994. The transduction 
of blue light signals in higher plants. Annu. Rev. Plant Physiol. Plant Mol. Biol. 45:14371

Smith H. 1995. Physiological and ecological function within the phytochrome family. Annu. Rev. Plant Physiol. Plant Mol. Biol. 46:289-315

Somers DE, Quail PH. 1995. Temporal and spatial expression patterns of $P H Y A$ and $P H Y B$ genes in Arabidopsis. Plant J. 7:413-27

Somers DE, Sharrock RA, Tepperman JM, Quail PH. 1991. The hy3 long hypocotyl mutant of Arabidopsis is deficient in phytochrome B. Plant Cell 3:1263-74

Spain BH, Bowdish KS, Pacal AR, FlückigerStaub S, Koo D, et al. 1996. Two human cDNAs, including a homolog of Arabidopsis FUS6 (COP11), suppress G-protein- and mitogen-activated protein kinase-mediated signal transduction in yeast and mammalian cells. Mol. Cell. Biol. 16:6698-706

Staub JM, Wei N, Deng X-W. 1996. Evidence for FUS6 as a component of the nuclearlocalized COP9 complex in Arabidopsis. Plant Cell 8:2047-56

Stockhaus J, Nagatani A, Halfter U, Kay S, Furuya M, Chua N-H. 1992. Serine-to-alanine substitutions at the amino-terminal region of phytochrome A result in an increase in biological activity. Genes Dev. 6:2364-72

Szekeres M, Németh K, Koncz-Kálmán Z, Mathur J, Kauschmann A, et al. 1996. Brassinosteroids rescue the deficiency of CYP90, a cytochrome $\mathrm{P} 450$, controlling cell elongation and de-etiolation in Arabidopsis. Cell 85:171-82

Takahashi T, Gasch A, Nishizawa N, Chua N-H. 1995. The DIMINUTO gene of Arabiodpsis is involved in regulating cell elongation. Genes Dev. 9:97-107

Terry MJ. 1997. Phytochrome chromophoredeficient mutants. Plant Cell Environ. In press

Terzaghi WB, Cashmore AR. 1995. Lightregulated transcription. Annu. Rev. Plant Physiol. Plant Mol. Biol. 46:445-74

von Arnim AG, Deng X-W. 1994. Light inactivation of Arabidopsis photomorphogenic repressior COP1 involves in cell-specific regulation of its nucleocytoplasmic partitioning. Cell 79:1035-45

von Arnim A, Deng X-W. 1996. Light control of seedling development. Annu. Rev. Plant Physiol. Plant Mol. Biol. 47:215-43

Wagner D, Fairchild CD, Kuhn RM, Quail PH. 1996a. Chromophore-bearing $\mathrm{NH}_{2}$-terminal domains of phytochromes A and B determine their photosensory specificity and differential light lability. Proc. Natl. Acad. Sci. USA 93:4011-15

Wagner D, Koloszvari M, Quail PH. 1996 b. Two small spatially distinct regions of phytochrome B are required for efficient signaling rates. Plant Cell 8:859-71

Wagner D, Quail PH. 1995. Mutational analysis of phytochrome B identifies a small $\mathrm{COOH}-$ terminal-domain region critical for regulatory activity. Proc. Natl. Acad. Sci. USA 92:8596-600

Wagner D, Tepperman JM, Quail PH. 1991. Overexpression of phytochrome B induces a short hypocotyl phenotype in transgenic Arabidopsis. Plant Cell 3:1275-88

Wang A-Y, Kenigsbuch D, Sun L, Harel E, Ong MS, Tobin EM. 1997. A Myb-related transcription factor is involved in the phytochrome regulation of an Arabidopsis Lhcb gene. Plant Cell 9:491-507

Wei N, Deng X-W. 1992. COP9: a new genetic locus involved in light-regulated development and gene expression in Arabidopsis. Plant Cell 4:1507-18

Wei N, Deng X-W. 1996. The role of the COP/DET/FUS genes in light control of Arabidopsis seedling development. Plant Physiol. 112:871-78

Whitelam GC, Johnson E, Peng J, Carol P, Anderson ML, et al. 1993. Phytochrome A null mutants of Arabidopsis display a wild-type phenotype in white light. Plant Cell 5:75768

Wong Y-S, Cheng H-C, Walsh DA, Lagarias JC. 1986. Phosphorylation of Avena phytochrome in vitro as a probe of lightinduced conformational changes. J. Biol. Chem. 261:12089-97

Wu S-H, Lagarias JC. 1996. The methylotrophic yeast Pichia pastoris synthesizes a functionally active chromophore precursor of the plant photoreceptor phytochrome. Proc. Natl. Acad. Sci. USA 93:8989-94

Xu Y, Parks BM, Short TW, Quail PH. 1995. Missense mutations define a restricted segment in the C-terminal domain of phytochrome A critical to its regulatory activity. Plant Cell 7:1433-43

Zagotta MT, Hicks KA, Jacobs CI, Young JC, Hangarter RP, Meeks-Wagner DR. 1996. The Arabidopsis ELF3 gene regulates vegetative photomorphogenesis and the photoperiodic induction of flowering. Plant J. 10:691702 